\title{
Substitution Boosts Charge Separation for High Solar-Driven Photocatalytic Performance
}

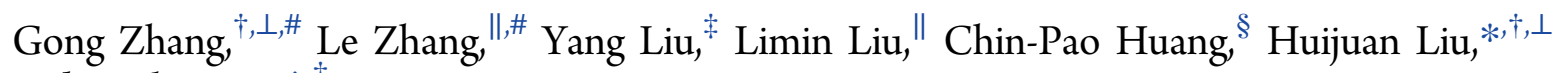 \\ and Jinghong $\mathrm{Li}^{*}$,
}
${ }^{\dagger}$ State Key Laboratory of Environmental Aquatic Chemistry, Research Center for Eco-Environmental Sciences, Chinese Academy of Sciences, Beijing 100085, China
${ }^{\ddagger}$ Department of Chemistry, Key Laboratory of Bioorganic Phosphorus Chemistry \& Chemical Biology, Beijing Key Laboratory for Microanalytical Methods and Instrumentation, Tsinghua University, Beijing 100084, China
${ }^{\S}$ Department of Civil and Environmental Engineering, University of Delaware, Newark, Delaware 19716, United States
"Beijing Computational Science Research Center, Beijing 100084, China
${ }^{\perp}$ University of Chinese Academy of Sciences, Beijing 100039, China

\section{Supporting Information}

ABSTRACT: Bandgap engineering of photocatalysts is a common approach to achieving high effective utilization of solar resource. However, the difficulty in achieving bandgap narrowing and high activity simultaneously seems to be irreconcilable via the traditional modification pathway. Herein, we have substituted iodine for a fraction of bromine atoms in $\mathrm{BiOBr}$ to overcome this restriction and provided some deep-seated insights into how the substitution boosts the photocatalytic properties. The substituted $\mathrm{BiOBr}_{0.75} \mathrm{I}_{0.25}$ exhibited exceptional photoactivity, with photon-to-current conversion efficiency approximately 6 times greater than $\mathrm{TiO}_{2}$ in $\mathrm{UV}$ region, and more than 10 times higher than $\mathrm{BiOBr}$ or $\mathrm{BiOI}$ in visible-light region. We found that the substitution narrowed the bandgap, facilitated the diffusion of

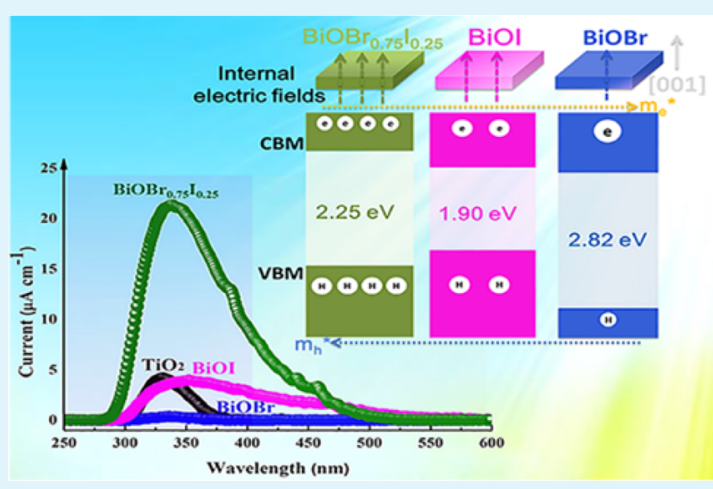
electron with small effective mass, as well as induced oxygen vacancies on $\left[\mathrm{Bi}_{2} \mathrm{O}_{2}\right]^{2+}$ layers. By virtue of the stronger dipole moments produced, the enhancement of intrinsic electric fields between $\left[\mathrm{Bi}_{2} \mathrm{O}_{2}\right]^{2+}$ and halogen slabs was achieved in $\mathrm{BiOBr}_{0.75} \mathrm{I}_{0.25}$; thereby the distance the photogenerated electron could diffuse was sufficient to inhibit the recombination. Our findings not only shed light on the potential properties of hybrid-halide photocatalysts but also provide a strategy for developing high efficiency catalysts.

KEYWORDS: $\mathrm{BiOBr}$, iodine, substitution, vacancy, photoactivity

\section{INTRODUCTION}

Photocatalysts provide significant potential for the conversion of solar radiation to chemical energy. ${ }^{1-3}$ Different approaches for narrowing the bandgap have developed into an active pursuit by researchers aimed at gathering solar energy., 4 Doping, a common method for the modification of nanomaterials, is traditionally considered to be of crucial and scientific significance in materials science. ${ }^{6}$ Unfortunately, the difficulty of simultaneously achieving bandgap narrowing and high photoactivity seems to be irreconcilable. Although some success has been reported in achieving visible light activity by using dopants, the charge carrier trapping and recombination sites induced in the bulk have negative effects on photochemical activity. ${ }^{7,8}$

As the layered ternary semiconductors, bismuth oxyhalides ( $\mathrm{BiOX}, \mathrm{X}=\mathrm{Cl}, \mathrm{Br}$, and $\mathrm{I}$ ) with $\left[\mathrm{Bi}_{2} \mathrm{O}_{2}\right]^{2+}$ slabs sandwiched between halogen atom slabs have drawn extensive attention due to their superior photocatalytic performance, in some cases surpassing that of $\mathrm{TiO}_{2}$ in $\mathrm{UV}$ region. ${ }^{9-11}$ However, in contrast to some other Bi-based semiconductors (such as $\mathrm{BiVO}_{4}$, $\mathrm{Bi}_{2} \mathrm{WO}_{6}$, and $\left.\mathrm{BiFeO}_{3}\right),{ }^{12,13}$ lower visible-light activities of the $\mathrm{BiOX}$ need to be enhanced for satisfying practical applications. In BiOX crystals, the valence band is comprised of $\mathrm{X} n \mathrm{n}$ and $\mathrm{O}$ $2 p$ states, while the conduction band minimum (CBM) is dominated by $\mathrm{Bi} 6 \mathrm{p}$ states. The BiOX crystals may be vested in $\mathrm{O} 2 \mathrm{p}$ and $\mathrm{X} n \mathrm{p}$ to $\mathrm{Bi} 6 \mathrm{p}$, a $\mathrm{p}$-to-p charge-transfer type, and the bandgap can also be derived using the charge-transfer energy minus the valence-bandwidth. ${ }^{14}$ The charge-transfer energy is proportional to the Pauling electronegativity of $\mathrm{X}$ atom (3.16, 2.96, and 2.66 for $\mathrm{Cl}, \mathrm{Br}$, and $\mathrm{I}$, respectively), which shows an apparent trend of the bandgap narrowing with the $\mathrm{X}$ atomic number. Hence, there are numerous reports on the preparation of $\mathrm{BiOBr}$ or $\mathrm{BiOI}$ that have good visible-light photoactivity. ${ }^{15,16}$

Received: July 14, 2016

Accepted: September 23, 2016

Published: September 23, 2016 

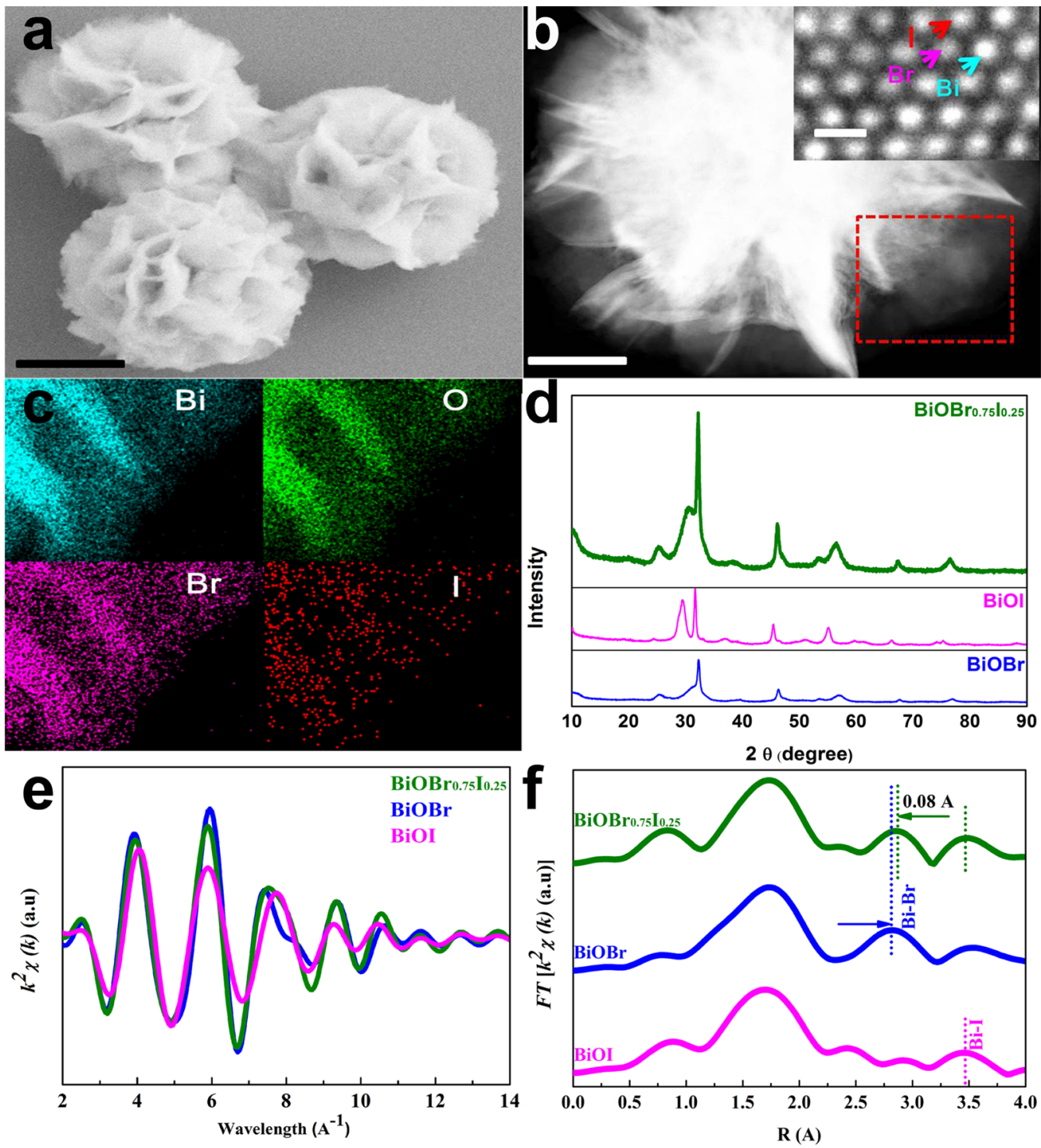

Figure 1. Characterizations of $\mathrm{BiOBr}_{0.75} \mathrm{I}_{0.25}$ sample. (a) SEM of the BiOBr${ }_{0.75} \mathrm{I}_{0.25}$. Scale bar, $500 \mathrm{~nm}$. (b) STEM image of the single BiOBr${ }_{0.75} \mathrm{I}_{0.25}$ nanosphere. Scale bar, $100 \mathrm{~nm}$. Inset: Magnified HAADF-STEM image of the $\mathrm{BiOBr}_{0.75} \mathrm{I}_{0.25}$ shell along with [010] direction, demonstrating the iodine is well distributed in the bromine host sites. Scale bar, $0.5 \mathrm{~nm}$. (c) The large area STEM-EDS mapping corresponding to the red dash quadrate in (b). (d) XRD patterns, (e) the Bi L-edge extended EXAFS oscillation, and (f) corresponding Fourier transform (FT) for the BiOBr, $\mathrm{BiOI}$, and $\mathrm{BiOBr}_{0.75} \mathrm{I}_{0.25}$.

Additionally, the intrinsic electric fields due to the dipole moments between the $\left[\mathrm{Bi}_{2} \mathrm{O}_{2}\right]^{2+}$ layer and the anionic halogen atoms also determine the separation of photogenerated charge carriers. ${ }^{17,18}$ With increasing halogen atomic number, the covalent bond between the $\mathrm{Bi}$ and $\mathrm{X}$ atoms is strengthened, which promotes the internal electric fields through an increase in the dipole moments; thereby the photogenerated charge carriers are separated effectively. ${ }^{19}$ Notably, in recently reported organic-inorganic mixed-halide perovskites, notwithstanding the coexistence of other elusive factors, remarkably enhanced photovoltaic performances have been indeed observed resulting from substitution. ${ }^{20,21}$ This has prompted us to hypothesize that the homogeneous substitution with foreign halogen atoms in $\mathrm{BiOX}$ would be feasible to achieve a strong intrinsic electric field for long charge diffusion length.

Meanwhile, during the process of pursuing optimized internal dipole moments, a few dangling bonds will be simultaneously created in the covalently bonded layers when strengthening the covalent bonding effect between bismuth and halogen atoms, resulting in vacancies in the crystal. ${ }^{22}$ Defects, as active sites where the charge carriers can be effectively separated, ${ }^{23,24}$ have been recently reported to narrow the band gap as well. ${ }^{25}$ Thus, the defect bismuth oxy-hybrid-halides have the potential to reconcile the apparent contradiction between bandgap narrowing and performance, and to provide an ideal platform to attain a comprehensive understanding of correlations between the structure, defects, and properties.

Herein, we report a detailed investigation on the substitution of iodine for bromine in $\mathrm{BiOBr}$ to optimize the performance through compositional tuning. The $\mathrm{BiOBr}_{0.75} \mathrm{I}_{0.25}$ exhibited exceptional photoactivity, with photon-to-current conversion efficiency approximately 6 times greater than $\mathrm{TiO}_{2}$ in the UV region, and more than 10 times higher than $\mathrm{BiOBr}$ or $\mathrm{BiOI}$ in the visible-light region. On the basis of the results of X-ray absorption fine structure (XAFS) spectra, positron annihilation lifetime spectra (PAS), and electron paramagnetic resonance 
(EPR) spectra in association with theoretical calculations, the relationships between substitution, vacancies, and enhanced activity were analyzed thoroughly.

\section{RESULTS AND DISCUSSION}

The substitution of iodine atoms into the BiOBr crystal should have the best potential for the preparation of highly efficient
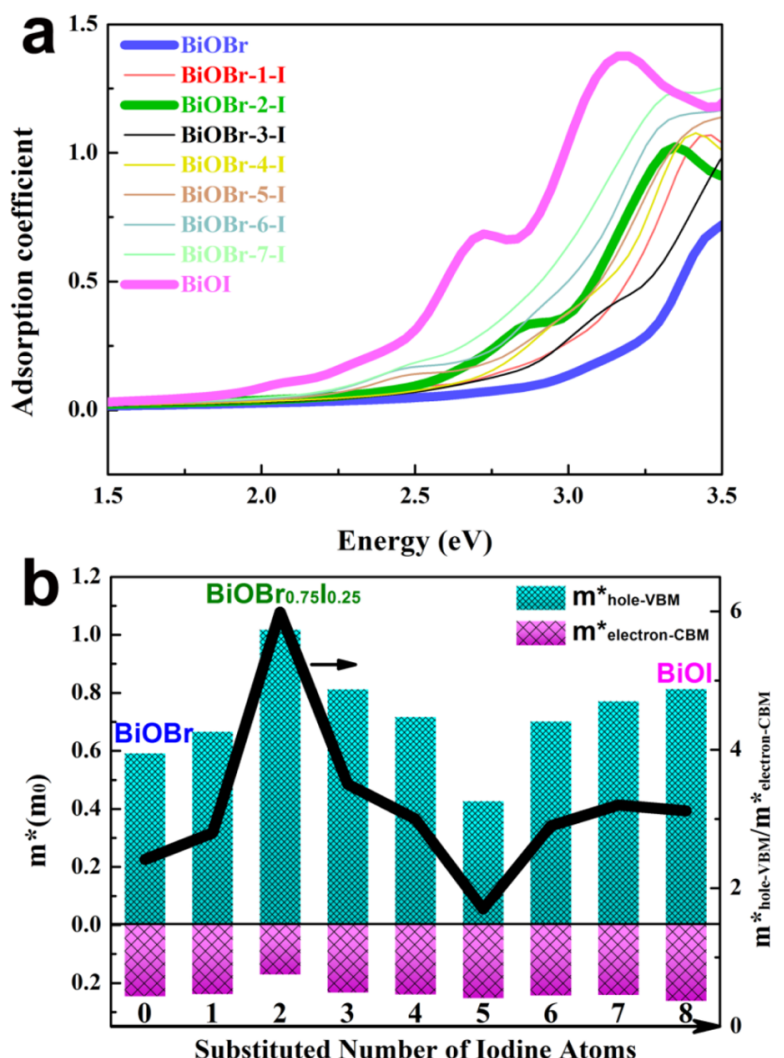

Figure 2. Theoretical calculation on the effect of substituted iodine numbers on BiOBr. (a) Computational optical absorption for the different substitution iodine atoms into $\mathrm{BiOBr}$. From density functional theory (DFT) calculations, pure $\mathrm{BiOBr}$ possesses a bandgap of $2.82 \mathrm{eV}$. With increase in the substituted numbers, the bandgap decreased from the $2.52 \mathrm{eV}$ in the two-iodine-atom substitution to $1.90 \mathrm{eV}$ in pure BiOI. (b) The effective mass approximation with various degrees of iodine atom substitution. The bold solid line is the ratio of $m^{*}$ (hole) to $m^{*}$ (electron), for quantitative analysis of the separation efficiency.

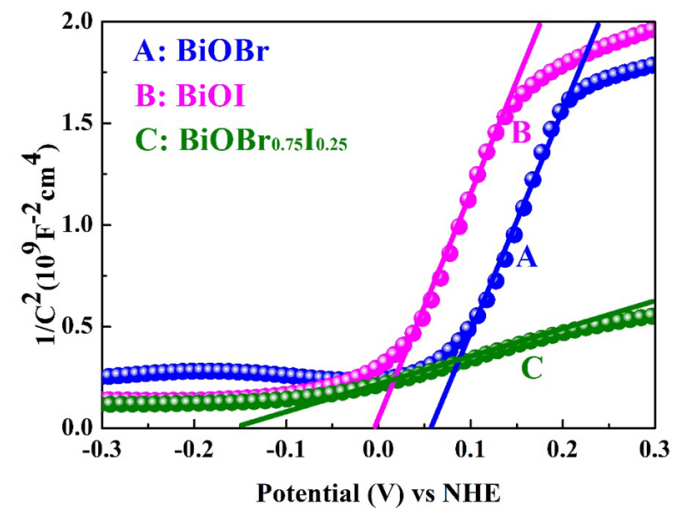

Figure 3. Mott-Schottky plots of $\mathrm{BiOBr}, \mathrm{BiOI}$, and $\mathrm{BiOBr}_{0.75} \mathrm{I}_{0.25}$ electrodes measured at $1000 \mathrm{~Hz}$. photocatalysts. Here, we achieve this by applying a facile solvothermal method (see Experimental Section). In contrast to the morphology range from flake to solid sphere with addition of different amounts of precursors (Figure S1), regular spheres with porous structure assembled from numerous smooth and flower-like nanoshells were observed in the case of $\mathrm{Bi}: \mathrm{Br}$ :I ratio of 1.0:1.5:1.5 (Figure $1 \mathrm{a}$ ), similar to $\mathrm{BiOBr}$ and BiOI. The sphere was further observed by high-angle annular dark-field scanning transmission electron microscopy (HAADF-STEM) (Figure 1b). Generally, the detector in HAADF gathers electrons that change high-angle scattering, the signal intensity of which is directly proportional to the atomic number, $Z .^{26,27}$ Therefore, the sharp contrast in the image enables the identification of the $\mathrm{Bi}(Z=83), \mathrm{Br}(Z=35)$, and $\mathrm{I}(Z=53)$ ions in shells. ${ }^{28}$ As shown in the inset in Figure $\mathrm{lb}$, the brightest spots symbolize $\mathrm{Bi}$ atoms, spots with the darkness represent $\mathrm{Br}$ atoms, and the spots with intermediate darkness stand for the I atoms, which are well-distributed in the $\mathrm{Br}$ host sites. Uniform distribution of $\mathrm{Bi}, \mathrm{O}, \mathrm{Br}$, and $\mathrm{I}$ was observed throughout the structure (Figure 1c). The elemental composition of the sample was analyzed via energy dispersive $\mathrm{X}$-ray spectroscopy (EDX). The $\mathrm{Bi}: \mathrm{Br}: \mathrm{I}$ atomic ratio was around 1:0.75:0.25, which was further confirmed through the ion chromatography (IC) and inductively coupled plasma optical emission spectrometry (ICP-OES). Moreover, on the basis of calculated reaction enthalpy (Figure S2), a stable bismuth oxy-hybrid-halide structure could be achieved by random substitution of iodine atoms into the $\mathrm{BiOBr}$ crystal. XRD pattern confirms that the sample has a tetragonal matlockite crystal structure (Figure 1d), representing a layered structure with $\left[\mathrm{Bi}_{2} \mathrm{O}_{2}\right]^{2+}$ interleaved between halogen atoms slabs. ${ }^{29}$ Meanwhile, in contrast to BET surface areas of 45.8 and $42.6 \mathrm{~m}^{2} \mathrm{~g}^{-1}$ of $\mathrm{BOBr}$ and $\mathrm{BiOI}$, a decreased value of $29.2 \mathrm{~m}^{2} \mathrm{~g}^{-1}$ was observed in $\mathrm{BiOBr}_{0.75} \mathrm{I}_{0.25}$ after iodine substitution (Figure S3).

Extended X-ray absorption fine structure spectroscopy (EXAFS) measurements were performed to study the arrangement of atoms around the photoabsorber. ${ }^{30}$ The Bi L-edge oscillation curve for $\mathrm{BiOBr} / \mathrm{I}$ displays a remarkable difference in comparison with those of unsubstituted $\mathrm{BiOBr}$ and $\mathrm{BiOI}$ (Figure 1e), indicating the different local atomic arrangements in the catalysts. ${ }^{31}$ Fourier transform (FT) curves present three peaks in the range from 1 to $4 \AA$, corresponding to $\mathrm{Bi}-\mathrm{O}, \mathrm{Bi}-$ $\mathrm{Br}$, and $\mathrm{Bi}-\mathrm{I}$ distances, respectively. The FT curve of $\mathrm{BiOBr}$ shows the $\mathrm{Bi}-\mathrm{Br}$ coordination with a main peak at $2.80 \AA$, whereas the peak is shifted to higher $R$ by $0.08 \AA$ in $\mathrm{BiOBr} / \mathrm{I}$. The high- $R$ shift of the $\mathrm{Bi}-\mathrm{Br}$ peak that resulted from the elongated distance between $\mathrm{Bi}$ and $\mathrm{Br}$ (Table S1) was due, most probably, to the electrostatic repulsion induced by the iodine with a smaller charge-to-mass ratio in $\mathrm{BiOBr} / \mathrm{I}$ (Figure $\mathrm{S} 4)$. On the contrary, the $\mathrm{Bi}-\mathrm{I}$ coordination is almost the same as that in BiOI. Thus, on the basis of the coordination information and the fitted distance between $\mathrm{Bi}$ and halogen atoms, the atom distributions in $\mathrm{BiOBr} / \mathrm{I}$ were established (Figure S5). Hence, we denoted the material as $\mathrm{BiOBr}_{0.75} \mathrm{I}_{0.25}$.

On the basis of the as-identified atom arrangements in $\mathrm{BiOBr}_{0.75} \mathrm{I}_{0.25}$, first-principle calculations were first performed to evaluate the effect of substitution on the band gap energy. $\mathrm{BiOBr}$ possesses a bandgap of $2.82 \mathrm{eV}$ (Figure 2a). The substitution of iodine atoms for $25 \%$ the bromine in the $\mathrm{BiOBr}$ crystal results in a sharp down-shift of $\mathrm{Bi} 6 \mathrm{p}$ orbitals to VBM, decreasing the bandgap to $2.52 \mathrm{eV}$ (Figure S6a). Further, carrier mobility, characterizing how rapidly an electron can 


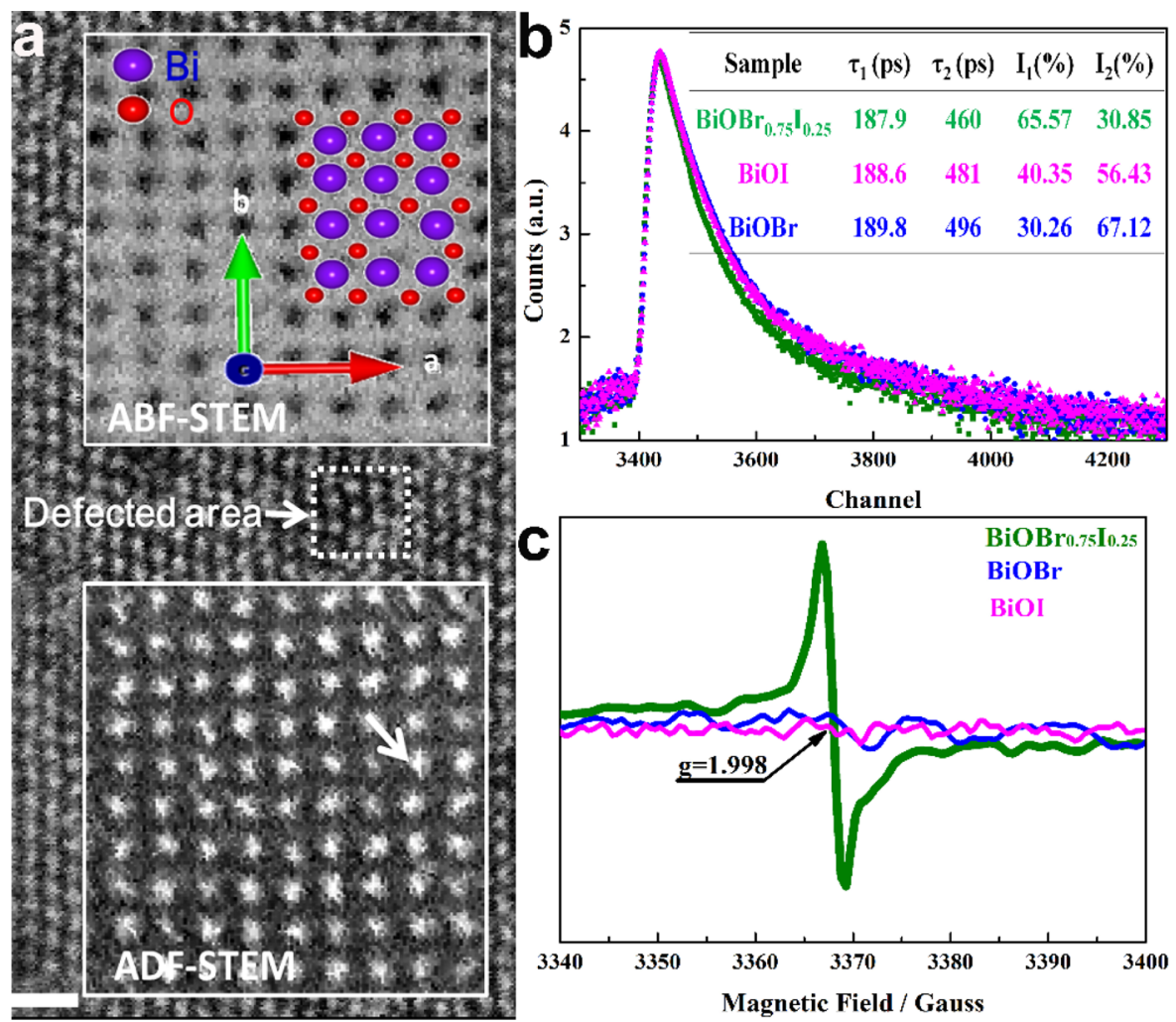

Figure 4. Formation of oxygen vacancies on $\mathrm{BiOBr}_{0.75} \mathrm{I}_{0.25}$. (a) The HRTEM image of $\left[\mathrm{Bi}_{2} \mathrm{O}_{2}\right]^{2+}$ layers ([001] direction), confirming the existence of defects on the layer. Scale bar, $2 \mathrm{~nm}$. Inset: Annular bright-field and dark-field STEM imaging in the white dash quadrate for visualizing atomic arrangements in the covalence layers (blue and red balls represent bismuth and oxygen atom, respectively). The white arrowhead in the dark-field STEM image indicates the shift of the bismuth atom, which might have resulted from the deficiency of oxygen atom on layer. (b) Positron annihilation lifetime spectra (PAS) with lifetime parameters (table inset), and (c) low temperature (70 K) $\mathrm{EPR}$ spectra of $\mathrm{BiOBr}$, BiOI, and $\mathrm{BiOBr}_{0.75} \mathrm{I}_{0.25}$, respectively.

transfer through materials under field, was investigated using effective mass approximation, to evaluate the effect of substitution on photoinduced carrier separation efficiency. ${ }^{32,33}$ In a semiconductor, the movement of electron takes place in a periodic potential, different from its motion in vacuum, and the effective mass $\left(m^{*}\right)$ is a quantity that is applied to simplify the band structure by constructing an analogy to the behavior of a free particle with the same mass. ${ }^{34} \mathrm{~A}$ particle with small effective mass means will have low inertia and high carrier mobility $(\mu)$ based on the formulas:

$$
\mu=\frac{e \tau_{\mathrm{s}}}{m^{*}}
$$

where $e$ and $\tau_{\mathrm{s}}$ are electron charge and mean scattering time, respectively. Remarkably, $\mathrm{BiOBr}_{0.75} \mathrm{I}_{0.25}$ exhibits the smallest $m_{\mathrm{e}}{ }^{*}$ (electron) and the largest $m_{\mathrm{h}}{ }^{*}$ (hole) among all of the compositions studied (Figure $2 \mathrm{~b}$ ), which suggests that the electron in the iodine-substituted material has the highest mobility. Moreover, iodine has a substantially larger radius than that of the atom it is replacing; thereby the equilibrium positions of the unsubstituted atoms nearby are shifted away from the original sites. Thus, the dipole moment for $\mathrm{BiOBr}_{0.75} \mathrm{I}_{0.25}$ increased to $2.98 \mathrm{D}$, with respect to the values of 1.70 and $2.45 \mathrm{D}$ for $\mathrm{BiOBr}$ and $\mathrm{BiOI}$. The enhanced intrinsic electric field due to the promoted dipole moment could facilitate the diffusion of the small effective mass $m_{\mathrm{e}}{ }^{*}$ to the trap sites, leaving the heavy hole at its original (VBM), which would effectively decrease their recombination probability. ${ }^{35}$
Mott-Schottky plots were constructed to determine the carrier density of $\mathrm{BiOBr}, \mathrm{BiOI}$, and $\mathrm{BiOBr}_{0.75} \mathrm{I}_{0.25}$, respectively. The observed positive slopes indicate the n-type nature of BiOX samples (Figure 3). ${ }^{36,37}$ The carrier density could be determined by the relation:

$$
N_{\mathrm{d}}=\left(\frac{2}{e \varepsilon \varepsilon_{\mathrm{o}}}\right)\left(\frac{\mathrm{d} C^{-2}}{\mathrm{~d} V}\right)^{-1}
$$

where $N_{\mathrm{d}}$ is the number of donors, $\varepsilon$ is the dielectric constant, $e$ is the electron charge, and $\varepsilon_{0}$ is vacuum permittivity. Notably, $\mathrm{BiOBr}_{0.75} \mathrm{I}_{0.25}$ exhibits an order of magnitude higher carrier density than $\mathrm{BiOBr}$ and $\mathrm{BiOI}$ (carrier densities for $\mathrm{BiOBr}, \mathrm{BiOI}$, and $\mathrm{BiOBr}_{0.75} \mathrm{I}_{0.25}$ were evaluated as $1.25 \times 10^{18}, 1.38 \times 10^{18}$, and $1.29 \times 10^{19}$, respectively). In addition, flat-band potential of $\mathrm{BiOBr}_{0.75} \mathrm{I}_{0.25}$ was negatively shifted, which depressed charge carriers' recombination by enhancing band bending at interface. ${ }^{38}$ Meanwhile, conduction band edges of n-type BiOX can be obtained from the following equation:

$$
V_{\mathrm{CB}}=U_{\mathrm{fb}}-\frac{K_{\mathrm{B}} T}{q} \ln \left(\frac{N_{\mathrm{D}}}{N_{\mathrm{C}}}\right)
$$

in which $N_{\mathrm{C}}$ is the density of states in CB; $q$ is unsigned charge of an electron. In contrast to the DOS result for defect-free $\mathrm{BiOBr}_{0.75} \mathrm{I}_{0.25}$, negative shifted CB in the Mott-Schottky plot was due to the presence of transition state induced by oxygen vacancies, which was in good agreement with the theoretical calculations as well. 

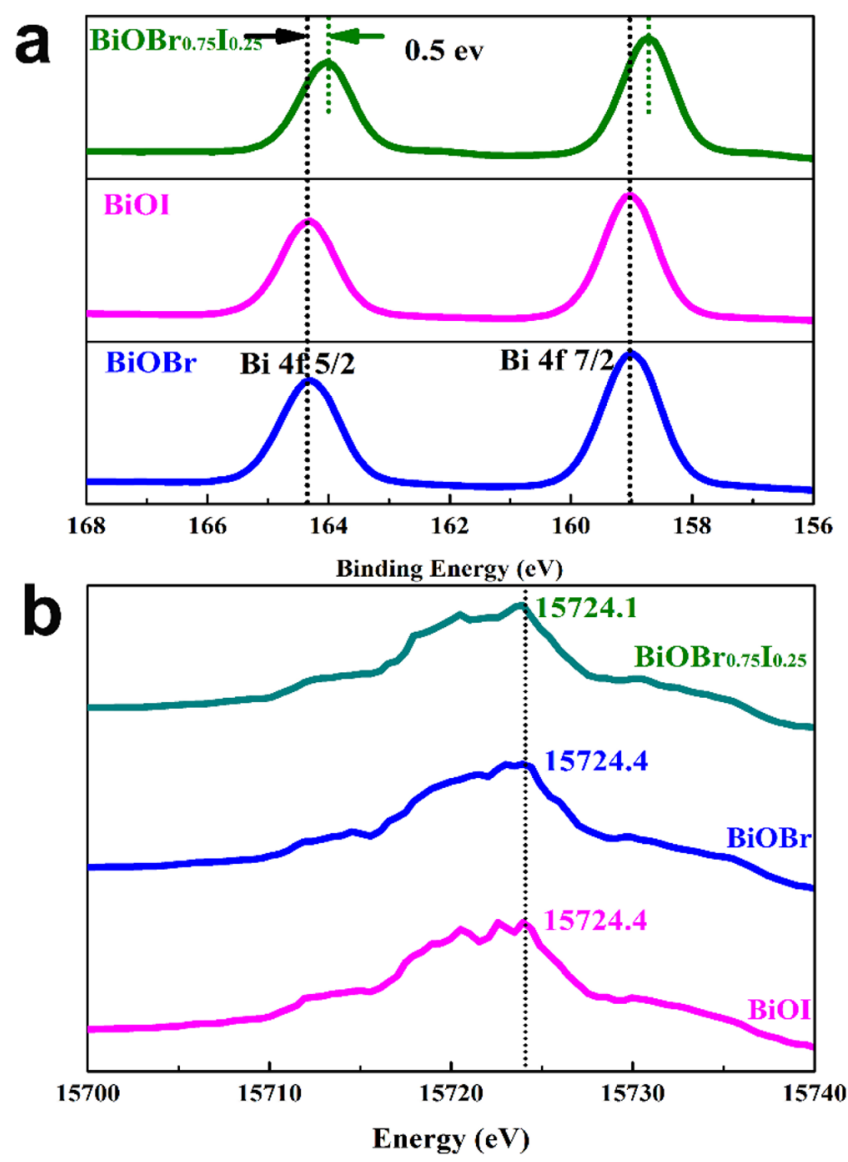

Figure 5. (a) High-resolution XPS scans for $\mathrm{Bi} 4 \mathrm{f}$, and (b) the firstorder derivative of $\mathrm{Bi}$ L-edge XANES measurements for $\mathrm{BiOBr}, \mathrm{BiOI}$, and $\mathrm{BiOBr}_{0.75} \mathrm{I}_{0.25}$, respectively.

As discussed above, the substitution of iodine atoms into the $\mathrm{BiOBr}$ crystal could improve the carrier density because of the large electron mobility. Remarkably, in some domains, a distorted lattice can be observed in $\left[\mathrm{Bi}_{2} \mathrm{O}_{2}\right]^{2+}$ layers (Figure $4 a$ ). Such lattice dislocation is usually derived from atom deficiency. It should also be noted that the oxygen vacancies can be regarded as electron donor species. ${ }^{39,40}$ To ascertain this, the nature of the defects was first studied by PAS. Figure $4 \mathrm{~b}$ depicts the three types of positron annihilation measurements for the $\mathrm{BiOX}$, and the table inset shows lifetime components of the two positrons, $\tau_{1}$ and $\tau_{2}$, with the corresponding intensities $I_{1}$ and $I_{2}$, respectively. Normally, $\tau_{1}$ was derived from the defects with small-size in bulk, while $\tau_{2}$ results from positrons trapped by defects with larger size on surface. ${ }^{41}$ According to the theoretically calculated lifetime of positrons, the short $\tau_{1}$ around 189 ps could be assigned to positron annihilation as trapped at the oxygen defects, while the other component $\left(\tau_{2}\right)$ around 460 ps was attributed to larger vacancy clusters on surface. Moreover, further information on the concentration of the vacancies could be gained from the relative intensity $(I)$. In comparison with the values of 0.45 and 0.71 of $\mathrm{BiOBr}$ and $\mathrm{BiOI}$, respectively, the $I_{1} / I_{2}$ value of $\mathrm{BiOBr}_{0.75} \mathrm{I}_{0.25}$ increased to 2.12 , indicating a higher concentration of defects after iodine substitution.

The underlying mechanism of the oxygen vacancy formation is, in fact, closely related to the generation of reduced states of bismuth with iodine substitution, and depended on the synthetic process as well. As observed in the electronic density distribution (Figure S6), the local atomic arrangement in $\mathrm{BiOBr}_{0.75} \mathrm{I}_{0.25}$ strengthens the covalent interaction between the bismuth and halogen atoms, resulting in remarkable variations in the electronic landscape around the $\mathrm{Bi}$ atoms. The enhancing covalency can also be quantitatively noticed according to effective ionic valence, which is the variance between Mulliken charge and primitive ionic charge in the compound. The average Mulliken charge of halogen atoms in $\mathrm{BiOBr}_{0.75} \mathrm{I}_{0.25}$ decreased to -0.22 with respect to that of -0.43 and -0.33 in $\mathrm{BiOBr}$ and $\mathrm{BiOI}$, respectively; the corresponding effective ionic valence increased from 0.57 and 0.67 to 0.78 (the primitive ionic charge of a halogen ion is -1.00). The greater value in $\mathrm{BiOBr}_{0.75} \mathrm{I}_{0.25}$ means a higher level of covalent interaction between the halogen elements and bismuth atoms. The binding energy of $\mathrm{Bi} 4 \mathrm{f}$ in the $\mathrm{BiOBr}_{0.75} \mathrm{I}_{0.25}$ is red-shifted by $0.5 \mathrm{eV}$ (Figure 5a), and the absorption edge energy of Bi species in first-order derivative of Bi L-edge XANES is red-shifted by 0.3 $\mathrm{eV}$ with respect to unsubstituted $\mathrm{BiOBr}$ and $\mathrm{BiOI}$ (Figure $5 \mathrm{~b}$ ), implying the presence of low valence state bismuth species. Moreover, during the solvothermal synthetic process, the $\mathrm{Bi}$ atoms possess inadequate oxygen as bonding partners to accommodate the valence variation. EPR spectra were then performed to gain more information on the $\mathrm{BiOBr}_{0.75} \mathrm{I}_{0.25}$. As shown in Figure $4 c$, both $\mathrm{BiOBr}$ and $\mathrm{BiOI}$ have a weak signal at $g=2.003$. On the contrary, $\mathrm{BiOBr}_{0.75} \mathrm{I}_{0.25}$ exhibits obvious EPR signal at $g=2.003$, indexing to the low-valence $\mathrm{Bi}$ atoms with dangling bonds located in the $\left[\mathrm{Bi}_{2} \mathrm{O}_{2}\right]^{2+}$ layers, ${ }^{42}$ bringing about a high concentration of oxygen vacancies (OVs) in the crystal. $^{43,44}$

The existence of OVs in the semiconductor greatly changes the Bader charges, band structure, partial density of states (PDOS), total density of states (TDOS), and frontier molecular orbitals (Figure 6). As above-mentioned, the substitution of iodine atoms into $\mathrm{BiOBr}$ decreased the bandgap by $0.30 \mathrm{eV}$. To further investigate the electron density contour maps, it must be noted that $\mathrm{Bi} 6 \mathrm{p}$ and $\mathrm{X} n \mathrm{p}$ states generated another high-density region in the presence of OVs, resulting in a sharp downshift of localized $\mathrm{Bi} 6 \mathrm{p}$ states and moderate downshift of the $\mathrm{X} n \mathrm{n}$ states, further narrowing the bandgap by $0.26 \mathrm{eV}$. This trend is consistent with the UV/vis diffuse reflection data (Figure S8). In addition, newly hybridized states between the $\mathrm{Bi} 6 \mathrm{p}$ and $\mathrm{X}$-np states created a transition energy band between CBM and VBM, which was also conducive to photon absorption. The occupied states near the Fermi level could be considered to consist of isolated and localized states, which were mainly due to the existence of reduced Bi species. The presence of the transition states will facilitate electron diffusion by the polaron hopping mechanism. ${ }^{45}$ Moreover, in contrast to defect-free material, the observed $k$-vector (crystal momentum) in the Brillouin zone for CB and VBM is different in the defected $\mathrm{BiOBr}_{0.75} \mathrm{I}_{0.25}$, indicating that it is of an indirect bandgap semiconductor. Hence, the recombination efficiency of as-generated electron-hole pairs is far slower than that in the defect-free material.

Further examination of electron density distribution demonstrated that the covalent interactions were strengthened between the halogen slabs and $\mathrm{Bi}$ atoms in the defect $\mathrm{BiOBr}_{0.75} \mathrm{I}_{0.25}$; thereby the dipole moment increased to 3.38 D. Additionally, the variation in electronic structures induced by the OVs implies that the electron-donor species can also serve as a dopant to enhance the electron mobility. According to the effective mass approximation, the electron effective mass was decreased by a factor of 1.5 in contrast to defect-free 


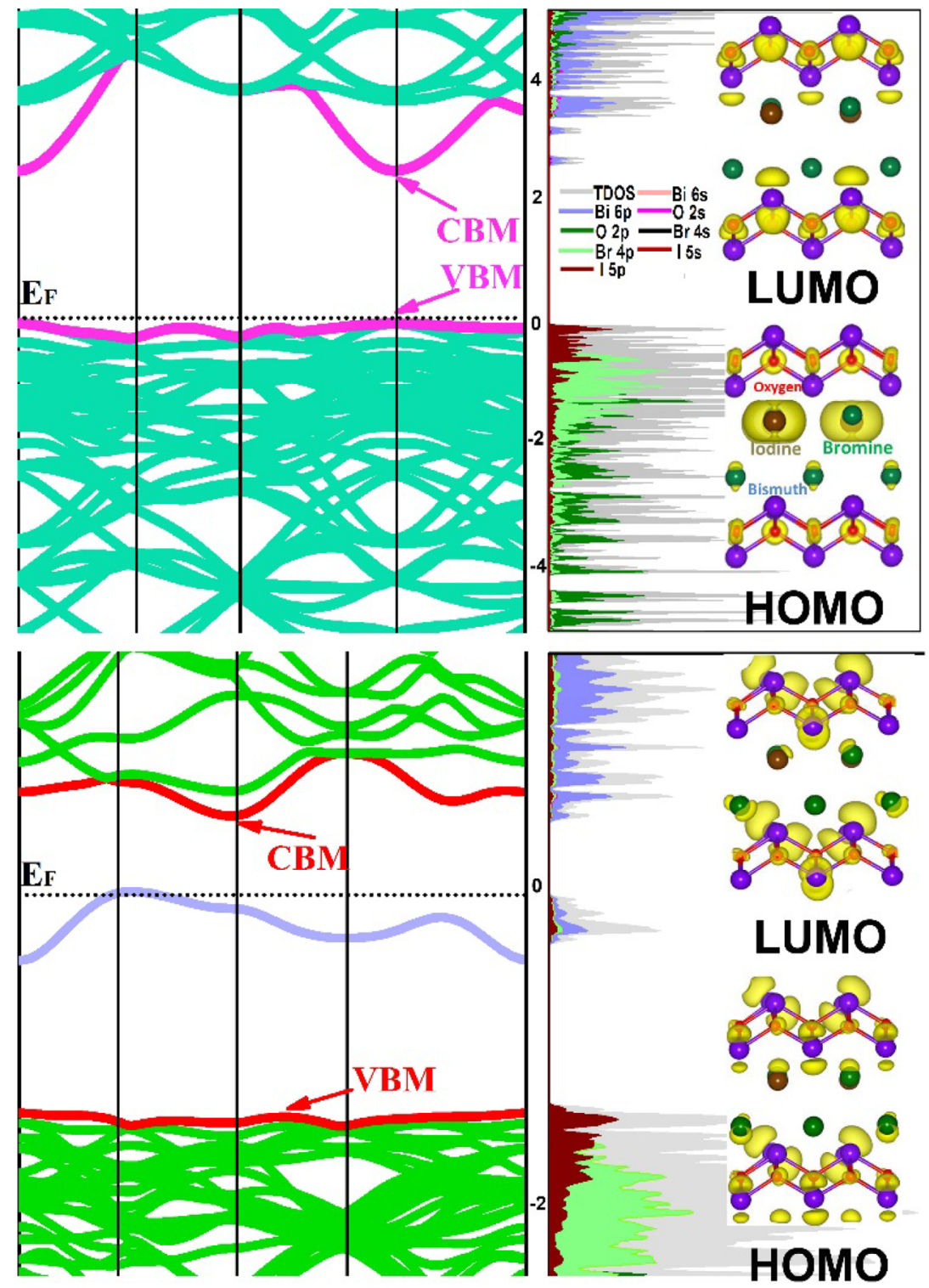

Figure 6. Band structure and density of electronic states of defect-free $\mathrm{BiOBr}_{0.75} \mathrm{I}_{0.25}$ (top) and the defected one (bottom). Inset: The electron density contour maps for the LUMO and HOMO, respectively.

material. The small effective mass with high mobility would effectively diffuse in the enhanced intrinsic electric fields, thereby inhibiting recombination.

The photon-to-current conversion efficiency of $\mathrm{BiOBr}_{0.75} \mathrm{I}_{0.25}$ was investigated by using the photocurrent action spectra and included the state-of-the-art $\mathrm{TiO}_{2}$ catalyst for comparison. Figure $7 \mathrm{a}$ shows that $\mathrm{BiOBr}$ has the lowest photocurrent, $\mathrm{BiOI}$ has an intermediate photon-to-current efficiency, and $\mathrm{BiO}$ $\mathrm{Br}_{0.75} \mathrm{I}_{0.25}$ achieves much higher photocurrent than $\mathrm{BiOBr}, \mathrm{BiOI}$, and $\mathrm{BiOBr}_{a} \mathrm{I}_{b}$ with other $\mathrm{Br}$ :I ratios in the UV-visible -light regions (Figure S8). The superior photoactivity of $\mathrm{BiOBr}_{0.75} \mathrm{I}_{0.25}$ is reasonably speculated to originate from its high carrier mobility, density, and the enhanced dipole moments. It must be noted that the maximum photocurrent of $\mathrm{BiOBr}_{0.75} \mathrm{I}_{0.25}$ was approximately 6 times greater than P25 TiO 2 toward light region from 330 to $350 \mathrm{~nm}$. In addition, chronoampermetric technique was applied for evaluating the photoresponse of catalysts. Upon power excitation, photocatalysts exhibited instantaneous photocurrents, which then sharply reverted to steady state after the light was turned off. $\mathrm{BiOBr}_{0.75} \mathrm{I}_{0.25}$, with the highest carrier mobility, exhibits a photocurrent density of

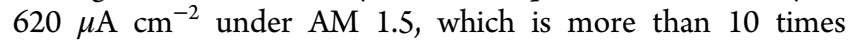
higher than $\mathrm{BiOBr}$ and $\mathrm{BiOI}$ (Figure $7 \mathrm{~b}$ ). A similar tendency is also observed under visible-light irradiation (Figure 7c).

The charge-transfer properties of the photocatalysts were further measured by means of electrochemical impedance spectrum (EIS) measurements. We selected equivalent circuit (EC) (Figure $7 \mathrm{~d}$, inset), which has been evidenced to be suitable in fitting Bi-based semiconductors, to fit the parameters in different electrochemical processes. Similar to the role of surface state reported in former literature, ${ }^{46-48}$ bulk defect crystals were here emphasized in EC model, which can not only trap holes from the valence band $\left(R_{\text {trapping }}\right)$, but similarly influence the transfer of holes from solid interface to the donor species in solution, as defined by $R_{\mathrm{ct}, \text { trap }}$. As shown in Figure $7 \mathrm{~d}$, the electrical resistance of $\mathrm{BiOBr}_{0.75} \mathrm{I}_{0.25}$ was much smaller than that of $\mathrm{BiOBr}$ and $\mathrm{BiOI}$ in the dark as indicated by smaller impedance arc radius, which was undoubtedly attributed to the existence of OVs with high concentration after substitution. Under light illumination, the smaller charge-transfer resistance 

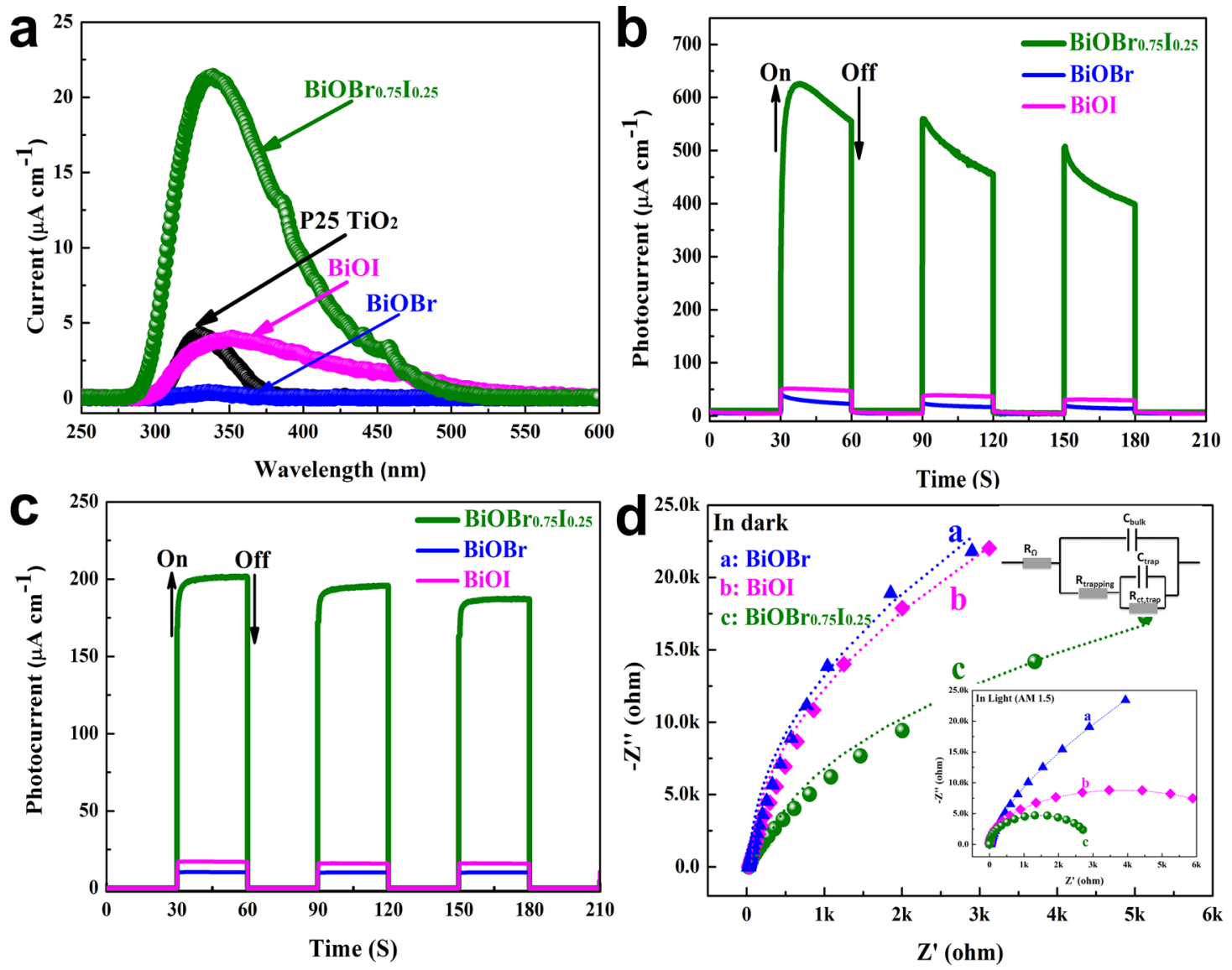

Figure 7. Photoelectrochemical properties. (a) The photon-to-current conversion efficiencies of $\mathrm{BiOBr}, \mathrm{BiOI}$, and $\mathrm{BiOBr}_{0.75} \mathrm{I}_{0.25}$ measured using photocurrent action spectra in UV and visible light, and photoresponse recorded by chronoamperometry at $+0.5 \mathrm{~V}$ in (b) solar or (c) visible light irradiation, respectively. (d) Nyquist plots for the electrochemical impedance spectroscopy (EIS) obtained from $0.1 \mathrm{~Hz}$ to $100 \mathrm{kHz}$ in dark and light (AM 1.5) irradiation (inset) with an inserted equivalent circuit for fitting the data, where $C_{\mathrm{d}}$ is the double-layer capacitance, $R_{\mathrm{s}}$ is electrolyte resistance, $R_{\text {trapping }}$ represents the resistance during the process of trapping carriers by surface states, $C_{\text {trap }}$ represents the amount of active sites in surface states, and $R_{\mathrm{ct} \text { trap }}$ is the value of charge-transfer resistance.

$\left(R_{\mathrm{ct} \text {, trap }}\right)$ on the surface of $\mathrm{BiOBr}_{0.75} \mathrm{I}_{0.25}$ resulted from the enhanced diffusion of electrons with high mobility (Table S2). Meanwhile, the $C_{\text {trap }}$ value, which reflects the quantity of trapped carriers in surface states, was $4.9 \times 10^{-4} \mathrm{~F} \mathrm{~cm}^{-2}$ in $\mathrm{BiOBr}_{0.75} \mathrm{I}_{0.25}$, in sharp contrast to the values of $6.1 \times 10^{-5}$ and $4.7 \times 10^{-5} \mathrm{~F} \mathrm{~cm}^{-2}$ in $\mathrm{BiOI}$ and $\mathrm{BiOBr}$. The increase in $C_{\text {trap }}$ is ascribed to the larger quantities of photoinduced holes on the surface.

Moreover, the photocatalytic performance of the $\mathrm{BiOX}$ materials was evaluated. First, with UV light (200-400 nm) irradiation, the red-color of Rhodamine (RB) was totally degraded by $\mathrm{BiOBr}_{0.75} \mathrm{I}_{0.25}$ within $5 \mathrm{~min}$, whereas $20 \mathrm{~min}$ was needed with $\mathrm{TiO}_{2}$. Under visible light, pseudo-first-order kinetics was fitted well in degradations, and the apparent rate constant $(k)$ of $1.2 \mathrm{~min}^{-1}$ was calculated for $\mathrm{BiOBr}_{0.75} \mathrm{I}_{0.25}$, which was in sharp contrast to that of 0.32 and $0.067 \mathrm{~min}^{-1}$ with $\mathrm{BiOI}$ and $\mathrm{BiOBr}$ (Figure 8a). In contrast to $\mathrm{BiVO}_{4}$, a stateof-the-art Bi-based material for photocatalytic splitting water, defect-rich $\mathrm{BiOBr}_{0.75} \mathrm{I}_{0.25}$ catalyst exhibited the higher photocatalytic efficiency to the colored chemicals. ${ }^{49}$ Meanwhile, due to the suitable iodine substitution as well as the as-induced active oxygen vacancies, degradation efficiency for $\mathrm{RB}$ under the same light irradiation outperformed other $\mathrm{BiOBr}_{\mathrm{a}} \mathrm{I}_{\mathrm{b}}$ samples

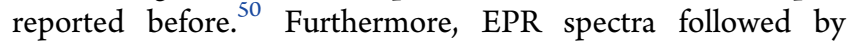
radical-trapping were carried out to gain deep insights into reactions. ${ }^{51}$ An intensity ratio of 1:2:2:1 in 4-fold characteristic peak was observed for $\mathrm{DMPO}-{ }^{\circ} \mathrm{OH}$ adduct in $\mathrm{BiOBr}{ }^{29}$ Notably, a seven-line spectrum characteristic signal with higher intensity was observed for the $\mathrm{BiOBr}_{0.75} \mathrm{I}_{0.25}$ (Figure $8 \mathrm{~b}$ ). The results show that the reaction of the excited electrons or holes with oxygen in aqueous suspension is able to generate a significant amount of oxidant as shown by the formation of 5,5dimethy 1-2-pyrrolidone- $N$-oxyl (DMPOX).$^{52}$ In addition, the photogenerated charge carriers participated in the photocatalytic reaction directly, which was confirmed by the photocatalytic oxidation of Bisphenol A (BPA), and reduction of $\mathrm{Cr}^{\mathrm{VI}}$ in neutral conditions. BPA, which has been reported to cause adverse effects on aquatic organisms, ${ }^{53}$ was chosen as a probe to assess the role of holes in degradation. ${ }^{54}$ Under solar light, the degradation rate constant $(k)$ is $0.19 \mathrm{~min}^{-1}$ in $\mathrm{BiOBr}_{0.75} \mathrm{I}_{0.25}$, which is approximately 7 times that of $\mathrm{TiO}_{2}$, indicating the direct attack by a high concentration of holes (Figure 8c). Meanwhile, the reduction of $\mathrm{Cr}^{\mathrm{VI}}$ was completed in 30 min with $\mathrm{BiOBr}_{0.75} \mathrm{I}_{0.25}$ at a rate constant $0.056 \mathrm{~min}^{-1}$, while negligible $\mathrm{H}_{2} \mathrm{O}_{2}$ was detected, implying that the $\mathrm{Cr}^{\mathrm{VI}}$ was reduced by these photogenerated electrons (Figure $8 \mathrm{~d}$ ). The photoactivities of $\mathrm{BiOBr}_{0.75} \mathrm{I}_{0.25}$ over 10 consecutive cycles for three contaminants containing solutions are shown in Figure S10. A decreased catalytic efficacy after 10 cycles can be observed in the RB- and $\mathrm{Cr}^{\mathrm{VI}}$-containing solutions, which were 

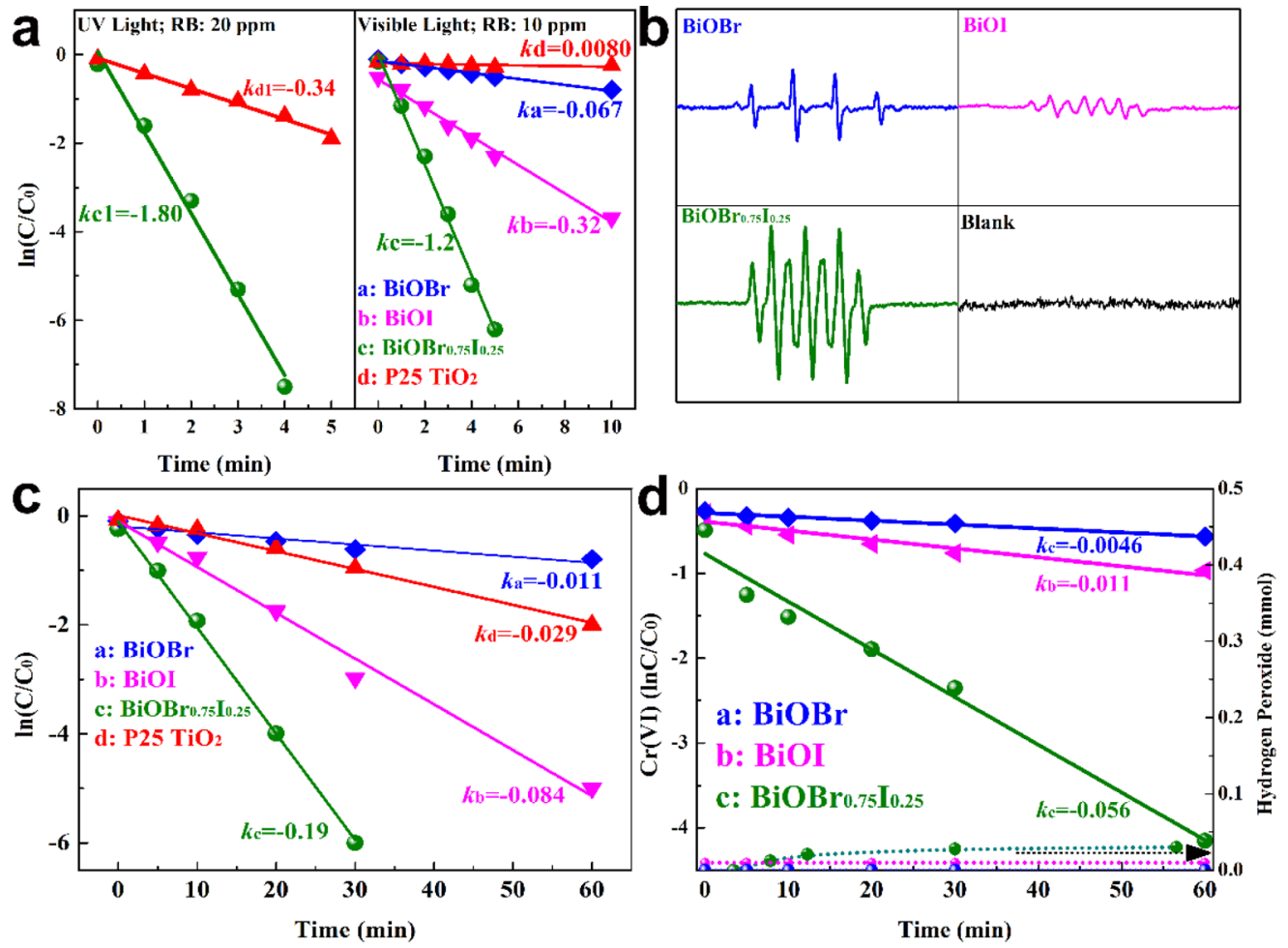

Figure 8. Photocatalytic performances. (a) Photocatalytic degradation of $\mathrm{RB}\left(20 \mathrm{mg} \mathrm{L}^{-1}\right)$ with $0.02 \mathrm{~g}$ of $\mathrm{BiOBr}_{0.75} \mathrm{I}_{0.25}$ or $\mathrm{P} 25 \mathrm{TiO}_{2}$ under $\mathrm{UV}$ light (left), and degradation of $\mathrm{RB}\left(10 \mathrm{mg} \mathrm{L}{ }^{-1}\right)$ at a load of $0.02 \mathrm{~g}$ of $\mathrm{BiOBr}, \mathrm{BiOI}, \mathrm{BiOBr}_{0.75} \mathrm{I}_{0.25}$, or $\mathrm{P} 25 \mathrm{TiO}_{2}$ catalysts under visible light (right). (b) EPR spectra for $\mathrm{BiOBr}$, $\mathrm{BiOI}$, and $\mathrm{BiOBr}_{0.75} \mathrm{I}_{0.25}$ in DMPO-containing solutions under solar light irradiation. (c) Photocatalytic oxidation of BPA and (d) reduction of $\mathrm{Cr}^{\mathrm{VI}}$ at neutral $\mathrm{pH}$ condition under solar light irradiation.

due to a strong adsorptive effect with $\mathrm{RB}$, and deposition of asreduced $\mathrm{Cr}^{\mathrm{III}}$ on surface in neutral condition. The photocatalytic degradation to BPA in the 10th almost remained the same as the first time. Overall, the observed stability was an important attribution for practical application of $\mathrm{BiOBr}_{0.75} \mathrm{I}_{0.25}$ to environmental remediation.

\section{CONCLUSIONS}

In summary, we here prepared oxygen-vacancy-rich bismuth oxy-hybrid-halide photocatalysts by substitution of iodine atoms into $\mathrm{BiOBr}$ crystal, which was confirmed by quantitative analysis of the corresponding EXAFS regions. Results of experimental observations and theoretical calculations showed that the iodine substitution narrowed the bandgap, promoted the carrier mobility, and could be regarded as a prerequisite for the formation of oxygen vacancies. The photocatalytic experiments showed that the vacancy-rich structure constructed by substitution reconciled the apparent contradiction between bandgap narrowing and high activity; striking enhancements were achieved in photon-to-current conversion efficiency in both UV and visible-light regions. The results led to a greater mechanistic understanding of the synergistic effect in hybridhalide photocatalysts, for example, in hybrid-halide perovskite solar cells. ${ }^{55}$ The relationships among the structure, defects, and enhanced properties will provide a theoretical foundation for the design of a highly efficient catalyst.

\section{EXPERIMENTAL SECTION}

Materials Synthesis. $2.0 \mathrm{~g}$ of polyvinylpyrrolidone (PVP) $\left(M_{\mathrm{w}}=\right.$ $30000)$ (Aldrich) was added to $40 \mathrm{~mL}$ of hot ethylene glycol $\left(70^{\circ} \mathrm{C}\right)$ to obtain a homogeneous solution, and then $1 \mathrm{mmol}$ of $\mathrm{Bi}\left(\mathrm{NO}_{3}\right)_{3}$. $5 \mathrm{H}_{2} \mathrm{O}$ (Alfa) was carefully dissolved in $2 \mathrm{~min}$. Meanwhile, $1.5 \mathrm{mmol}$ of
Table 1. Reaction Details and Ratios of the As-Obtained Bi$\mathrm{Br}-\mathrm{I}$ in the $\mathrm{BiOBr}_{a} \mathrm{I}_{b}$

\begin{tabular}{ccclc}
$\mathrm{Bi}\left(\mathrm{NO}_{3}\right)_{3}(\mathrm{mmol})$ & $\mathrm{KBr}(\mathrm{mmol})$ & $\mathrm{KI}(\mathrm{mmol})$ & \multicolumn{1}{c}{$\mathrm{Bi}: \mathrm{Br}: \mathrm{I}$} & temp $/{ }^{\circ} \mathrm{C}$ \\
1.00 & 0.00 & 1.50 & $1: 0: 1$ & 150 \\
1.00 & 0.50 & 0.50 & $1: 0.65: 0.12$ & 150 \\
1.00 & 0.50 & 1.5 & $1: 0.25: 0.72$ & 150 \\
1.00 & 1.00 & 1.00 & $1: 0.45: 0.48$ & 160 \\
1.00 & 1.25 & 1.50 & $1: 0.70: 0.22$ & 160 \\
1.00 & 1.50 & 0.00 & $1: 1: 0$ & 160 \\
\hline
\end{tabular}

$\mathrm{KBr}$ was added under ultrasound, and subsequently $1.5 \mathrm{mmol}$ of $\mathrm{KI}$ was added into the reaction mixture. The mixture was then kept in a Teflon-lined autoclave (filled to $80 \%$ of its entire capacity), which was sealed and placed in an electric oven at $160{ }^{\circ} \mathrm{C}$ for $12 \mathrm{~h}$. When the Teflon-lined autoclave was allowed to cool at room temperature, paleyellow precipitate was filtered. The washing procedure was repeated several times with distilled water and absolute ethanol.

Additionally, for preparing samples with different substitution levels, the procedures were the same as for the $\mathrm{BiOBr}_{0.75} \mathrm{I}_{0.25}$ except that the amounts of halogen precursors and reaction temperatures were adjusted accordingly (Table 1 ).

Characterizations for Bismuth Oxyhalides. The particle size, composition, and crystal structure of the sample were characterized by powder X-ray diffraction (XRD) (PANalytical Inc.) equipped with Cu $\mathrm{K} \alpha$ irradiation. Morphologies of the samples were observed by Zeiss field emission scanning electron microscopy (FESEM). Transmission electron microscopy (TEM) was measured using a high-resolution JEM-ARM200F TEM/STEM for exploring the information on structure and lattice. X-ray photoelectron spectroscopy (XPS) was conducted in a PHI5000 Versa Probe system (Physical Electronics, $\mathrm{MN})$ using monochromatic $\mathrm{Al} \mathrm{K} \alpha$ radiation $(225 \mathrm{~W}, 15 \mathrm{~mA}, 15 \mathrm{kV})$, and the binding energy was calibrated with internal standard by use of C 1s peak at $284.80 \mathrm{eV}$. To explore light absorbance and emission behavior, UV-visible absorption spectra were recorded in diffuse 
reflection mode (UV2401/2, Shimadzu, Japan). Positron annihilation lifetime spectra (PAS) measurements were performed via a fast-slow coincident method. X-ray absorption fine structure spectroscopy (XAFS) for Bi L-edge was carried out at the Shanghai Synchrotron Radiation Facility (SSRF) on beamline BL14W1.

Photoelectrochemical Measurements. A two-electrode configuration system was used for photocurrent action spectra, ${ }^{56}$ where catalysts were covered on FTO glasses by the surgical-blade method applied as a working electrode (a glass rod was applied to roll the pastes containing $0.2 \mathrm{~g}$ of powder and $0.5 \mathrm{~mL}$ of ethanol on FTO) in $0.2 \mathrm{M} \mathrm{KCl}$ electrolyte; a platinum wire with high purity served as a counter electrode. Light source was a $300 \mathrm{~W}$ xenon lamp equipped with a monochromator, and PEC cell with an illumination area of 0.12 $\mathrm{cm}^{2}$ was illuminated from the FTO side. A lock-in amplifier synchronized with light chopper (monochromatic illuminating intensity was evaluated about $15 \mu \mathrm{W} / \mathrm{cm}^{2}$ ) was applied for recording the current signal. $\mathrm{P} 25 \mathrm{TiO}_{2}$-coated photoelectrode was first applied as the control. Photoelectrochemical properties were measured in a standard three-electrode configuration using a Princeton Versa STAT 3 electrochemical workstation, with $\mathrm{BiOX}$ electrodes as photoanodes; $\mathrm{Pt}$ wire and an $\mathrm{Ag} / \mathrm{AgCl}$ electrode were applied as counter and reference electrodes in $\mathrm{KCl}$ electrolyte, respectively. The light was from an AM 1.5 solar power system, whose wavelength below $420 \mathrm{~nm}$ was removed to achieve visible light by an optical filter.

Photocatalytic Test. Photocatalytic effectiveness was investigated by oxidation of Rhodamine B (RB), Bisphenol A (BPA), and the reduction of $\mathrm{Cr}^{\mathrm{VI}}$ in an initial concentration of $10 \mathrm{mg} \mathrm{L}^{-1}$. Specifically, $20 \mathrm{mg}$ of catalyst was added to $50 \mathrm{~mL}$ of solution containing the above chemicals. Before light irradiation, to attain adsorptive equilibrium, mixtures were mixed in the dark about $60 \mathrm{~min}$. After a predetermined time, samples were withdrawn for analyzing the concentration of the chemicals. In cycle runs, the photocatalytic reaction was 5, 20, and 30 $\min$ for $\mathrm{RB}, \mathrm{BPA}$, and $\mathrm{Cr}^{\mathrm{VI}}$, respectively. The concentration of $\mathrm{RB}$ was detected by UV/vis spectrophotometry (UV2401/2, Shimadzu). Residual concentration of BPA was determined via an Agilent high performance liquid chromatography (HPLC) system through a C18 column. For BPA, the mobile phase was the mixture of methanol and ultrapure water with a volume ratio of 30:70. Hexavalent chromium was detected at $540 \mathrm{~nm}$ via the 1,5-diphenylcarbazid analytical method following the AFNOR standard NFT $90-043 .{ }^{57} \mathrm{H}_{2} \mathrm{O}_{2}$ was analyzed spectrophotometrically at $400 \mathrm{~nm}$ applying potassium titanium oxalate solution. ${ }^{58}$

Computational Details for Bismuth Oxyhalides. All of the calculations were conducted by the Vienna ab initio simulation package (VASP), and the Perdew-Burke-Ernzerhof (PBE) exchangecorrelation functional within the generalized gradient approximation (GGA) was employed. ${ }^{59}$ The cutoff energy for basis set was set to 450 $\mathrm{eV}$. Brillouin zone was sampled with a $4 \times 4 \times 4 k$-mesh of Monkhorst-Park scheme. ${ }^{60}$ When treating valence-core interactions with 5,6 , and 7 valence electrons for $\mathrm{Bi}, \mathrm{O}$, and $\mathrm{X}(\mathrm{X}=\mathrm{Br}, \mathrm{I})$, the projector augmented-wave method (PAW) was used. Structures were relaxed until residual force on atomic individual was less than $0.01 \mathrm{eV}$ $/ \AA$. The BiOX are a sort of layered compounds with $P 4 / \mathrm{nmm}$ space group. $\mathrm{BiOX}$ were composed by $\left[\mathrm{Bi}_{2} \mathrm{O}_{2}\right]^{2+}$ layers and two sheets of $\mathrm{X}$ ions arranged in a sandwiched way. In this work, a $2 \times 2 \times 1$ supercell was applied for all calculations.

\section{ASSOCIATED CONTENT}

\section{S Supporting Information}

The Supporting Information is available free of charge on the ACS Publications website at DOI: 10.1021/acsami.6b08676.

Experimental details, partial results of calculations, and some characterizations (PDF)

\section{AUTHOR INFORMATION}

\section{Corresponding Authors}

*E-mail: hjliu@rcees.ac.cn.

*E-mail: jhli@mail.tsinghua.edu.cn.

\section{Author Contributions}

${ }^{\#}$ G.Z. and L.Z. contributed equally to this work.

Notes

The authors declare no competing financial interest.

\section{ACKNOWLEDGMENTS}

This work was financially supported by the National Science Fund for Distinguished Young Scholars of China (Grant no. 51225805), the Funds for Creative Research Groups of China (no. 51221892), National Key Research and Development Program of China (no. 2016YFA0203101), National Basic Research Program of China (no. 2013CB934004), National Natural Science Foundation of China (no. 51572139), and Tsinghua University Initiative Scientific Research Program.

\section{REFERENCES}

(1) Linic, S.; Christopher, P.; Ingram, D. B. Plasmonic-Metal Nanostructures for Efficient Conversion of Solar to Chemical Energy. Nat. Mater. 2011, 10, 911-921.

(2) Zhao, Z.; Tian, J.; Sang, Y.; Cabot, A.; Liu, H. Structure, Synthesis, and Applications of $\mathrm{TiO}_{2}$ Nanobelts. Adv. Mater. 2015, 27, 2557-2582.

(3) Huang, G.; Chen, Y. Z.; Jiang, H. L. Metal-Organic Frameworks for Catalysis. Huaxue Xuebao 2016, 74, 113-129.

(4) Han, R. B.; Lu, S.; Wang, Y. J.; Zhang, X. H.; Wu, Q.; He, T. Application of $\mathrm{SO}_{4}{ }^{2-}$ and $\mathrm{I}^{-}$Co-Doped Polyaniline Counter Electrode in Dye-sensitized Solar Cells. Acta Chim. Sin. 2015, 73, 1061-1068.

(5) Li, J.; Zhao, K.; Yu, Y.; Zhang, L. Facet-Level Mechanistic Insights into General Homogeneous Carbon Doping for Enhanced Solar-to-Hydrogen Conversion. Adv. Funct. Mater. 2015, 25, 21892201.

(6) Khan, S. U. M.; Al-Shahry, M.; Ingler, W. B. Efficient Photochemical Water Splitting by a Chemically Modified $\mathrm{n}-\mathrm{TiO}_{2}$. Science 2002, 297, 2243-2245.

(7) Tao, J.; Luttrell, T.; Batzill, M. A Two-Dimensional Phase of $\mathrm{TiO}_{2}$ with a Reduced Bandgap. Nat. Chem. 2011, 3, 296-300.

(8) Wang, J.; Tafen, D. N.; Lewis, J. P.; Hong, Z.; Manivannan, A.; Zhi, M.; Li, M.; Wu, N. Origin of Photocatalytic Activity of NitrogenDoped $\mathrm{TiO}_{2}$ Nanobelts. J. Am. Chem. Soc. 2009, 131, 12290-12297.

(9) Jiang, J.; Zhao, K.; Xiao, X.; Zhang, L. Synthesis and FacetDependent Photoreactivity of BiOCl Single-Crystalline Nanosheets. J. Am. Chem. Soc. 2012, 134, 4473-4476.

(10) Zhao, K.; Zhang, L.; Wang, J.; Li, Q.; He, W.; Yin, J. J. Surface Structure-Dependent Molecular Oxygen Activation of BiOCl SingleCrystalline Nanosheets. J. Am. Chem. Soc. 2013, 135, 15750-15753.

(11) Wang, H.; You, T. T.; Shi, W. W.; Li, J. H.; Guo, L. Au/TiO $/$ $\mathrm{Au}$ as a Plasmonic Coupling Photocatalyst. J. Phys. Chem. C 2012, 116, 6490-6494.

(12) Martinez Suarez, C.; Hernández, S.; Russo, N. $\mathrm{BiVO}_{4}$ as Photocatalyst for Solar Fuels Production through Water Splitting: A Short Review. Appl. Catal., A 2015, 504, 158-170.

(13) Murcia-López, S.; Fàbrega, C.; Monllor-Satoca, D.; HernándezAlonso, M. D.; Penelas -Pérez, G.; Morata, A.; Morante, J. R.; Andreu, T. Tailoring Multilayered $\mathrm{BiVO}_{4}$ Photoanodes by Pulsed Laser Deposition for Water Splitting. ACS Appl. Mater. Interfaces 2016, 8, 4076-4085.

(14) Huang, W. L.; Zhu, Q. DFT Calculations on the Electronic Structures of $\mathrm{BiOX}(\mathrm{X}=\mathrm{F}, \mathrm{Cl}, \mathrm{Br}, \mathrm{I})$ Photocatalysts with and without Semicore Bi 5d States. J. Comput. Chem. 2009, 30, 183-190.

(15) Li, H.; Shang, J.; Ai, Z.; Zhang, L. Efficient Visible Light Nitrogen Fixation with BiOBr Nanosheets of Oxygen Vacancies on the Exposed \{001\} Facets. J. Am. Chem. Soc. 2015, 137, 6393-6399.

(16) Zhang, H.; Yang, Y.; Zhou, Z.; Zhao, Y.; Liu, L. Enhanced Photocatalytic Properties in BiOBr Nanosheets with Dominantly Exposed (102) Facets. J. Phys. Chem. C 2014, 118, 14662-14669. 
(17) Myung, Y.; Wu, F.; Banerjee, S.; Park, J.; Banerjee, P. Electrical Conductivity of P-type BiOCl Nanosheets. Chem. Commun. 2015, 51, 2629-2632.

(18) Li, J.; Yu, Y.; Zhang, L. Bismuth Oxyhalide Nanomaterials: Layered Structures Meet Photocatalysis. Nanoscale 2014, 6, 84738488 .

(19) Sato, J.; Kobayashi, H.; Inoue, Y. Photocatalytic Activity for Water Decomposition of Indates with Octahedrally Coordinated d10 Configuration. II. Roles of Geometric and Electronic Structures. J. Phys. Chem. B 2003, 107, 7970-7975.

(20) Eperon, G. E.; Stranks, S. D.; Menelaou, C.; Johnston, M. B.; Herz, L. M.; Snaith, H. J. Formamidinium Lead Trihalide: A Broadly Tunable Perovskite for Efficient Planar Heterojunction Solar Cells. Energy Environ. Sci. 2014, 7, 982-988.

(21) Antonietta Loi, M.; Hummelen, J. C. Hybrid Solar Cells: Perovskites under the Sun. Nat. Mater. 2013, 12, 1087-1089.

(22) Ma, Y. W.; Lu, Y. H.; Yi, J. B.; Feng, Y. P.; Herng, T. S.; Liu, X.; Gao, D. Q.; Xue, D. S.; Xue, J. M.; Ouyang, J. Y.; Ding, J. Room Temperature Ferromagnetism in Teflon due to Carbon Dangling Bonds. Nat. Commun. 2012, 3, 727.

(23) Zuo, F.; Wang, L.; Wu, T.; Zhang, Z.; Borchardt, D.; Feng, P. Self-Doped $\mathrm{Ti}^{3+}$ Enhanced Photocatalyst for Hydrogen Production under Visible Light. J. Am. Chem. Soc. 2010, 132, 11856-11857.

(24) Xie, K.; Umezawa, N.; Zhang, N.; Reunchan, P.; Zhang, Y.; Ye, J. Self-Doped $\mathrm{SrTiO}_{3}$-Delta Photocatalyst with Enhanced Activity for Artificial Photosynthesis under Visible Light. Energy Environ. Sci. 2011, 4, 4211-4219.

(25) Guan, M.; Xiao, C.; Zhang, J.; Fan, S.; An, R.; Cheng, Q.; Xie, J.; Zhou, M.; Ye, B.; Xie, Y. Vacancy Associates Promoting Solar-Driven Photocatalytic Activity of Ultrathin Bismuth Oxychloride Nanosheets. J. Am. Chem. Soc. 2013, 135, 10411-10417.

(26) Patrick, B.; Ham, H. C.; Shao-Horn, Y.; Allard, L. F.; Hwang, G. S.; Ferreira, P. J. Atomic Structure and Composition of " $\mathrm{Pt}_{3} \mathrm{Co}$ " Nanocatalysts in Fuel Cells: An Aberration-Corrected STEM HAADF Study. Chem. Mater. 2013, 25, 530-535.

(27) Zhang, X.; Meng, F.; Christianson, J. R.; Arroyo-Torres, C.; Lukowski, M. A.; Liang, D.; Schmidt, J. R.; Jin, S. Vertical Heterostructures of Layered Metal Chalcogenides by Van Der Waals Epitaxy. Nano Lett. 2014, 14, 3047-3054.

(28) He, S.; Li, C.; Chen, H.; Su, D.; Zhang, B.; Cao, X.; Wang, B.; Wei, M.; Evans, D. G.; Duan, X. A Surface Defect-Promoted Ni Nanocatalyst with Simultaneously Enhanced Activity and Stability. Chem. Mater. 2013, 25, 1040-1046.

(29) Liu, G.; Wang, T.; Ouyang, S.; Liu, L.; Jiang, H.; Yu, Q.; Kako, T.; Ye, J. Band-Structure -Controlled $\mathrm{BiO}(\mathrm{ClBr})((1-\mathrm{x}) / 2) \mathrm{I}-\mathrm{x}$ Solid Solutions for Visible-Light Photocatalysis. J. Mater. Chem. A 2015, 3, 8123-8132.

(30) Zitolo, A.; Goellner, V.; Armel, V.; Sougrati, M.-T.; Mineva, T.; Stievano, L.; Fonda, E.; Jaouen, F. Identification of Catalytic Sites for Oxygen Reduction in Iron- and Nitrogen-Doped Graphene Materials. Nat. Mater. 2015, 14, 937.

(31) Liu, Y.; Cheng, H.; Lyu, M.; Fan, S.; Liu, Q.; Zhang, W.; Zhi, Y.; Wang, C.; Xiao, C.; Wei, S.; Ye, B.; Xie, Y. Low Overpotential in Vacancy-Rich Ultrathin $\mathrm{CoSe}_{2}$ Nanosheets for Water Oxidation. J. Am. Chem. Soc. 2014, 136, 15670-15675.

(32) Long, M.; Tang, L.; Wang, D.; Li, Y.; Shuai, Z. Electronic Structure and Carrier Mobility in Graphdiyne Sheet and Nanoribbons: Theoretical Predictions. ACS Nano 2011, 5, 2593-2600.

(33) Bardeen, J.; Shockley, W. Deformation Potentials and Mobilities in Non-Polar Crystals. Phys. Rev. 1950, 80, 72-80.

(34) Pekar, S. The Method Effective Electron Mass in Crystals. Zh. Eksperimentalnoi Teor. Fiz. 1946, 16, 933-935.

(35) Jin, H.; Wiendlocha, B.; Heremans, J. P. P-type Doping of Elemental Bismuth with Indium, Gallium and Tin: A Novel Doping Mechanism in Solids. Energy Environ. Sci. 2015, 8, 2027-2040.

(36) Liu, G.; Wang, T.; Zhou, W.; Meng, X.; Zhang, H.; Liu, H.; Kako, T.; Ye, J. Crystal-Facet-Dependent Hot-Electron Transfer in Plasmonic-Au/Semiconductor Heterostructures for Efficient Solar Photocatalysis. J. Mater. Chem. C 2015, 3, 7538-7542.
(37) Bai, S.; Jiang, J.; Zhang, Q.; Xiong, Y. Steering Charge Kinetics in Photocatalysis: Intersection of Materials Syntheses, Characterization Techniques and Theoretical Simulations. Chem. Soc. Rev. 2015, 44, 2893-2939.

(38) Wang, G.; Wang, H.; Ling, Y.; Tang, Y.; Yang, X.; Fitzmorris, R. C.; Wang, C.; Zhang, J. Z.; Li, Y. Hydrogen-Treated $\mathrm{TiO}_{2}$ Nanowire Arrays for Photoelectrochemical Water Splitting. Nano Lett. 2011, 11, 3026-3033.

(39) Zhang, Y.; Jiang, S.; Song, W.; Zhou, P.; Ji, H.; Ma, W.; Hao, W.; Chen, C.; Zhao, J. Nonmetal P-doped Hematite Photoanode with Enhanced Electron Mobility and High Water Oxidation Activity. Energy Environ. Sci. 2015, 8, 1231-1236.

(40) Kim, H.-i.; Monllor-Satoca, D.; Kim, W.; Choi, W. N-doped $\mathrm{TiO}_{2}$ Nanotubes Voated with A Thin $\mathrm{TaO}_{\mathrm{x}} \mathrm{N}_{\mathrm{y}}$ Layer for Photoelectrochemical Water Splitting: Dual Bulk and Surface Modification of Photoanodes. Energy Environ. Sci. 2015, 8, 247-257.

(41) Tuomisto, F.; Makkonen, I. Defect Identification in Semiconductors with Positron Annihilation: Experiment and Theory. Rev. Mod. Phys. 2013, 85, 1583-1631.

(42) Wang, S.; Pan, L.; Song, J.-J.; Mi, W.; Zou, J.-J.; Wang, L.; Zhang, X. Titanium-Defected Undoped Anatase $\mathrm{TiO}_{2}$ with P-Type Conductivity, Room-Temperature Ferromagnetism, and Remarkable Photocatalytic Performance. J. Am. Chem. Soc. 2015, 137, 2975-2983.

(43) Rettie, A. J. E.; Klavetter, K. C.; Lin, J.-F.; Dolocan, A.; Celio, H.; Ishiekwene, A.; Bolton, H. L.; Pearson, K. N.; Hahn, N. T.; Mullins, C. B. Improved Visible Light Harvesting of $\mathrm{WO}_{3}$ by Incorporation of Sulfur or Iodine: A Tale of Two Impurities. Chem. Mater. 2014, 26, 1670-1677.

(44) Akimov, A. V.; Neukirch, A. J.; Prezhdo, O. V. Theoretical Insights into Photoinduced Charge Transfer and Catalysis at Oxide Interfaces. Chem. Rev. 2013, 113, 4496-4565.

(45) Ling, Y.; Wang, G.; Reddy, J.; Wang, C.; Zhang, J. Z.; Li, Y. The Influence of Oxygen Content on the Thermal Activation of Hematite Nanowires. Angew. Chem., Int. Ed. 2012, 51, 4074-4079.

(46) Hernández, S.; Thalluri, S. M.; Sacco, A.; Bensaid, S.; Saracco, G.; Russo, N. Photo- Catalytic Activity of $\mathrm{BiVO}_{4}$ Thin-Film Electrodes for Solar-Driven Water Splitting. Appl. Catal., A 2015, 504, 266-271.

(47) Klahr, B.; Gimenez, S.; Fabregat-Santiago, F.; Hamann, T.; Bisquert, J. Water Oxidation at Hematite Photoelectrodes: The Role of Surface States. J. Am. Chem. Soc. 2012, 134, 4294-4302.

(48) Badia-Bou, L.; Mas-Marza, E.; Rodenas, P.; Barea, E. M.; Fabregat-Santiago, F.; Gimenez, S.; Peris, E.; Bisquert, J. Water Oxidation at Hematite Photoelectrodes with an Iridium-Based Catalyst. J. Phys. Chem. C 2013, 117, 3826-3833.

(49) Zhang, L.; Chen, D.; Jiao, X. Monoclinic Structured $\mathrm{BiVO}_{4}$ Nanosheets: Hydrothermal Preparation, Formation Mechanism, and Coloristic and Photocatalytic Properties. J. Phys. Chem. B 2006, 110, $2668-2673$.

(50) Zhang, X.; Zhang, L. Electronic and Band Structure Tuning of Ternary Semiconductor Photocatalysts by Self Doping: The Case of BiOI. J. Phys. Chem. C 2010, 114, 18198-18206.

(51) Lei, Y.; Chen, C.-S.; Tu, Y.-J.; Huang, Y.-H.; Zhang, H. Heterogeneous Degradation of Organic Pollutants by Persulfate Activated by $\mathrm{CuO}-\mathrm{Fe}_{3} \mathrm{O}_{4}$ : Mechanism, Stability, and Effects of $\mathrm{pH}$ and Bicarbonate Ions. Environ. Sci. Technol. 2015, 49, 6838-6845.

(52) Rajh, T.; Dimitrijevic, N. M.; Bissonnette, M.; Koritarov, T.; Konda, V. Titanium Dioxide in the Service of the Biomedical Revolution. Chem. Rev. 2014, 114, 10177-10216.

(53) Wang, X.; Qin, Y.; Zhu, L.; Tang, H. Nitrogen-Doped Reduced Graphene Oxide as a Bifunctional Material for Removing Bisphenols: Synergistic Effect between Adsorption and Catalysis. Environ. Sci. Technol. 2015, 49, 6855-6864.

(54) Wang, C.; Zhang, H.; Li, F.; Zhu, L. Degradation and Mineralization of Bisphenol $\mathrm{A}$ by Mesoporous $\mathrm{Bi}_{2} \mathrm{WO}_{6}$ under Simulated Solar Light Irradiation. Environ. Sci. Technol. 2010, 44, $6843-6848$

(55) Stranks, S. D.; Snaith, H. J. Metal-Halide Perovskites for Photovoltaic and Light-Emitting Devices. Nat. Nanotechnol. 2015, 10, 391-402. 
(56) Chen, D.; Zhang, H.; Liu, Y.; Li, J. Graphene and Its Derivatives for the Development of Solar Cells, Photoelectrochemical, and Photocatalytic Applications. Energy Environ. Sci. 2013, 6, 1362-1387.

(57) Demoisson, F.; Mullet, M.; Humbert, B. Pyrite Oxidation by Hexavalent Chromium: Investigation of the Chemical Processes by Monitoring of Aqueous Metal Species. Environ. Sci. Technol. 2005, 39, $8747-8752$.

(58) Yuan, S.; Fan, Y.; Zhang, Y.; Tong, M.; Liao, P. Pd-Catalytic In Situ Generation of $\mathrm{H}_{2} \mathrm{O}_{2}$ from $\mathrm{H}_{2}$ and $\mathrm{O}_{2}$ Produced by Water Electrolysis for the Efficient Electro-Fenton Degradation of Rhodamine B. Environ. Sci. Technol. 2011, 45, 8514-8520.

(59) Kresse, G.; Furthmuller, J. Efficient Iterative Schemes for Ab Initio Total-Energy Calculations Using a Plane-Wave Basis Set. Phys. Rev. B: Condens. Matter Mater. Phys. 1996, 54, 11169-11186.

(60) Perdew, J. P.; Burke, K.; Ernzerhof, M. Generalized Gradient Approximation Made Simple. Phys. Rev. Lett. 1996, 77, 3865-3868. 